\title{
The Relationship Between Endothelial Functions and HDL/LDL Ratios in Patients with Coronary Artery Disease
}

\author{
(1) Mehmet Kış, (1) Elton Soydan, (i) Mustafa Akın
}

Ege University Faculty of Medicine, Department of Cardiology, İzmir, Turkey

\begin{abstract}
Objectives: Endothelial dysfunction plays an important role in the initial stage of atherosclerosis, the growth of atherosclerotic plaque and the development of thrombogenic events. Low-density lipoprotein (LDL) cholesterol levels are associated with the risk of cardiovascular disease. It also inhibits endothelium-dependent vasodilation by disrupting the activity of nitric oxide (NO) synthase and causes endothelial dysfunction. It has been shown that high-density lipoprotein (HDL) cholesterol increases the production of $\mathrm{NO}$ and endothelial NO synthase that causes vascular dilatation directly or indirectly, and also supports endothelial cell migration and proliferation through different mechanisms. In our study, we aimed to investigate the relationship between HDL/LDL ratios and endothelial functions in patients with coronary artery disease (CAD) documented through coronary angiography (CAG).

Materials and Methods: Fifty-seven patients with CAD documented through CAG were included in the study. Endothelial functions were evaluated with the flow mediated vasodilation (FMD) test, which is the most commonly used non-invasive method for endothelial function assessment. In statistical analysis, the change in arterial diameter was examined by the paired sample t-test.

Results: The average age of 57 patients included in the study was $61.1 \pm 10.1$ years and $70 \%$ of these patients were male and $30 \%$ were female. The mean body mass index was $27.8 \pm 5.7 \mathrm{~kg} / \mathrm{m}^{2}$ and $57.9 \%$ of the patients were NYHA class I. In the FMD test, the mean radial artery percentage diameter change was found to be $12.61 \%( \pm 3.62)$. The average HDL/LDL ratio of the patients included in the study was $0.53( \pm 0.26)$, and the median value was 0.42 (minimum 0.27 - maximum 1.50). There was a weak positive correlation between HDL/LDL ratios and FMD percentage change $(\mathrm{r}=+0.379, \mathrm{p}=0.04)$.
\end{abstract}

Address for Correspondence: Mehmet Kış, Ege University Faculty of Medicine, Department of Cardiology, İzmir, Turkey e-mail: drmehmet.kis@hotmail.com ORCID: orcid.org/0000-0003-0775-8992

Received: 10.10.2020 Accepted: 05.12.2020

Cite this article as: Kış M, Soydan E, Akın M. The Relationship Between Endothelial Functions and HDL/LDL Ratios in Patients with Coronary Artery Disease. EJCM 2020;8(4):199-205.

DOI: 10.32596/ejcm.galenos.2020.10.055

${ }^{\circ}$ Copyright 2020 by Heart and Health Foundation of Turkey (TÜSAV) / E Journal of Cardiovascular Medicine published by Galenos Publishing House. 


\section{Abstract}

Conclusion: As HDL/LDL ratios increase in patients with CAD, the percentage change of flow-mediated dilatation, which is an indicator of endothelial functions, also increases.

Keywords: Coronary artery disease, endothelial dysfunction, HDL cholesterol, LDL cholesterol

\section{Introduction}

The endothelium is the largest organ of our body, which is located in the vascular system and plays an important role in the protection of vascular hemostasis in many physiological and pathological events ${ }^{(1-4)}$. The endothelium is a dynamic organ that can synthesize and release vasoconstrictor and vasodilator substances. When endothelial dysfunction occurs, the synthesis of factors such as nitric oxide (NO), which causes vasodilation, is impaired $^{(5)}$. Endothelial dysfunction plays an important role in the initial stage of atherosclerosis, atherosclerotic plaque growth, and development of thrombogenic events $^{(6)}$. Low-density lipoprotein (LDL) cholesterol levels are associated with the risk of cardiovascular disease and increase susceptibility to complications of atherosclerosis $^{(7)}$. Oxidized LDL inhibits endotheliumdependent vasodilation by disrupting the activity of NO synthase and causes endothelial dysfunction ${ }^{(8)}$. High density lipoprotein (HDL) has been shown to increase the production of NO and endothelial NO synthase causing vascular dilatation directly and indirectly, and it has been shown to support endothelial cell migration and proliferation through different mechanisms ${ }^{(9-11)}$. Literature information on the effects of HDL and LDL levels on vascular endothelial functions in patients with coronary artery disease (CAD) is partially insufficient. Therefore, in our study, we aimed to investigate the relationship between HDL/LDL ratios and endothelial functions in patients with $\mathrm{CAD}$ documented through coronary angiography (CAG).

\section{Materials and Methods}

Fifty-seven patients between the ages of 18 and 80 years, who had CAD documented through CAG, were included in the study. Patients who could not have a pulse from the radial artery, who could not have an optimal ultrasonographic evaluation, and who did not give informed consent were excluded from the study. In addition, patients with acute coronary syndrome and patients with normal coronary artery patency as a result of CAG were excluded from the analysis. Our study is a prospective, observational study. The clinical data of the patients were filled in the relevant places in the case report form. The medical treatment of the patients included in the study was arranged by the attending physician, and all patients were under optimal medical treatment in terms of CAD. Ethics committee approval of our study was obtained from Ege University Faculty of Medicine Clinical Research Ethics Committee on 26.12.2017 with the decision number 17-12.1/22. Written informed consent was obtained from all participants.

\section{Flow Mediated Vasodilation Test}

Endothelial functions were evaluated by using the flow mediated vasodilation (FMD) test. GE Healthcare Vivid E9 4D Cardiovascular Ultrasound System Device, 11L-D, 4.5-12 MHz probe was used for this test. The environment where the FMD test applied was quiet, at room temperature and bright. The FMD test was performed after eight hours of fasting, and patients had not consumed products such as caffeine, cigarettes, or tea that could affect the procedure. In FMD test, the arm cuff inflation till $220 \mathrm{mmHg}$ lasted for 5 minutes for the occlusion of the distal hand or distal forearm arteries. Then, the cuff was deflation. As a result, endothelial factors such as NO was released, causing vasodilation in response to reactive hyperemia in distal and proximal vascular beds were provided. In order to measure the maximum artery diameter, the arterial diameter change 
was recorded by ultrasonographic method for 3 minutes after the cuff was deflated.

FMD percentage change was made by calculating the following formula;

$\mathrm{FMD}=(\%)$ (Diameter after reactive hyperemia - Basal Arterial Diameter $)$ Basal Arterial Diameter

The radial artery diameter was measured in centimeters (cm) from the anterior wall intima to the posterior wall intima. Arterial diameter measurements were taken at the end of the diastole by determining the cardiac cycle with electrocardiography. The diameter and percentage change of the radial artery at baseline and after FMD were recorded.

\section{Statistical Analysis}

IBM SPSS Statistics 25.0 Program was used. The suitability of numerical variables to normal distribution was examined by using the Kolmogorv-Smirnov $(n \geq 50)$ and Shapiro-Wilk $(\mathrm{n}<50)$ tests. Numerical variables were given as mean and standard deviation or median (minimum-maximum). Categorical variables were given as numbers and percentages. The Mann-Whitney U test was used because it was not suitable for normal distribution. The change in arterial diameter was examined with the paired sample t-test. The relationship between numerical variables was analyzed by using the Spearman correlation analysis. The significance level was accepted as $<0.05$ for all hypotheses.

\section{Results}

While the average age of 57 patients included in the study was $61.1 \pm 10.1$ years, $70 \%$ of the patients were male and $30 \%$ were female. The mean body mass index was $27.8 \pm 5.7 \mathrm{~kg} / \mathrm{m}^{2}$ and $57.9 \%$ of the patients were New York Heart Association (NYHA) class I, 42.1\% were NYHA class II. The most common complaints of the patients were chest pain at a rate of $50.9 \%$ and dyspnea at a rate of $35.1 \%$. The complaint of palpitations was present in $8.8 \%$ of the patients. $29.8 \%$ of the patients had a history of smoking and $19.3 \%$ had a history of alcohol use. The demographic characteristics of the study population are summarized in Table 1. Hypertension was the most common comorbid disease in $78.9 \%$ of patients. Apart from hypertension, the most common comorbidities were diabetes at a rate of $38.6 \%$ and hyperlipidemia at a rate of $33.3 \%$, respectively. Five patients $(8.8 \%)$ had chronic obstructive pulmonary disease and four patients (7\%) had chronic kidney disease. Comorbid conditions of the patients included in the study are summarized in Table 2. Among the biochemical parameters, the mean urea value was $34.88( \pm 18.58)$, the mean HDL value was 44.88 $( \pm 10.86) \mathrm{mg} / \mathrm{dL}$, the LDL value was $96.86( \pm 35.90) \mathrm{mg} /$ $\mathrm{dL}$, the mean hemoglobin value was $13.52( \pm 2.25) \mathrm{g} / \mathrm{dL}$, and the mean fasting glucose value was $131.84( \pm 61.11)$ $\mathrm{mg} / \mathrm{dL}$. In echocardiography, the mean left ventricular ejection fraction value was $53.5 \pm 9.3 \%$, the mean LV enddiastolic diameter was $4.87( \pm 0.56) \mathrm{cm}$, and the left atrium (LA) diameter was $3.9 \pm 0.6 \mathrm{~cm}$. Laboratory and imaging findings of the patients are summarized in Table 3.

In the FMD test, the highest artery diameter was taken as basis in the measurements made during 3 minutes after hyperemia. The mean radial artery basal diameter was $0.25( \pm 0.029) \mathrm{cm}$, and the mean radial artery diameter after FMD was $0.28( \pm 0.033) \mathrm{cm}(\mathrm{p}<0.001)$. The mean

Table 1. Demographic characteristics of the study population

\begin{tabular}{|l|l|}
\hline Demographic features & (n=57) \\
\hline Age, year & $61.1 \pm 10.1$ \\
\hline Male sex, $\mathrm{n}(\%)$ & $40(70.1)$ \\
\hline $\mathrm{BMI}\left(\mathrm{kg} / \mathrm{m}^{2}\right)$ & $27.8 \pm 5.7$ \\
\hline Systolic BP, mmHg & $143.0 \pm 19.7$ \\
\hline Diastolic BP, mmHg & $79.7 \pm 13.6$ \\
\hline Heart rate/min & $76.4 \pm 13.6$ \\
\hline NYHA Class I, $\mathrm{n}(\%)$ & $33(57.9)$ \\
\hline NYHA Class II, $\mathrm{n}(\%)$ & $24(42.1)$ \\
\hline Chest pain, $\mathrm{n}(\%)$ & $29(50.9)$ \\
\hline Dyspnea, $\mathrm{n}(\%)$ & $20(35.1)$ \\
\hline Palpitation, $\mathrm{n}(\%)$ & $5(8.8)$ \\
\hline Smoking, $\mathrm{n}(\%)$ & $17(29.8)$ \\
\hline Alcohol use, $\mathrm{n}(\%)$ & $11(19.3)$ \\
\hline
\end{tabular}

BP: Blood pressure, NYHA: New York Heart Association, BMI: Body mass index, $n$ : Number 
radial artery percentage diameter change after FMD was $12.61 \%( \pm 3.62)$. FMD test findings are summarized in Table 4 , and the radial artery diameter change graph is shown in Figure 1.

The average HDL/LDL ratio of the patients included in the study was $0.53( \pm 0.26)$ and the median value was 0.42 (minimum 0.27 - maximum 1.50). There was a weak positive correlation between HDL/LDL ratios and

Table 2. Comorbid diseases in study population

\begin{tabular}{|l|l|}
\hline Comorbid diseases & $(\mathbf{n = 5 7 )}$ \\
\hline Hypertension, $\mathrm{n}(\%)$ & $45(78.9)$ \\
\hline Diabetes mellitus, $\mathrm{n}(\%)$ & $22(38.6)$ \\
\hline Hyperlipidemia, $\mathrm{n}(\%)$ & $19(33.3)$ \\
\hline $\mathrm{AF}, \mathrm{n}(\%)$ & $2(3.5)$ \\
\hline COPD, $\mathrm{n}(\%)$ & $5(8.8)$ \\
\hline Anemia, $\mathrm{n}(\%)$ & $6(10.5)$ \\
\hline Chronic HF, $\mathrm{n}(\%)$ & $4(7)$ \\
\hline CKD, $\mathrm{n}(\%)$ & $4(7)$ \\
\hline Thyroid disease, $\mathrm{n}(\%)$ & $3(5.3)$ \\
\hline $\begin{array}{l}\text { AF: Atrial fibrillation, CKD: Chronic kidney disease, COPD: Chronic } \\
\text { obstructive pulmonary disease, HF: Heart failure, } n: \text { Number }\end{array}$
\end{tabular}

Table 3. Laboratory and imaging findings of the patients

\begin{tabular}{|c|c|}
\hline Parameter & Mean ( \pm standard deviation) \\
\hline Urea, mg/dL & $34.88( \pm 18.58)$ \\
\hline Creatinine, mg/dL & $1.06( \pm 0.84)$ \\
\hline Total cholesterol, mg/dL & $169.68( \pm 41.03)$ \\
\hline $\mathrm{HDL}, \mathrm{mg} / \mathrm{dL}$ & $44.88( \pm 10.86)$ \\
\hline LDL, mg/dL & $96.86( \pm 35.90)$ \\
\hline HDL/LDL ratio & $0.53( \pm 0.26)$ \\
\hline $\mathrm{WBC}, \mathrm{k} / \mathrm{mm}^{3}$ & $8.45( \pm 2.59)$ \\
\hline Hemoglobin, g/dL & $13.52( \pm 2.25)$ \\
\hline Fasting glucose, mg/dL & $131.84( \pm 61.11)$ \\
\hline TSH, mU/L & $2.05( \pm 1.49)$ \\
\hline $\mathrm{Ca}, \mathrm{mg} / \mathrm{dL}$ & $9.45( \pm 0.67)$ \\
\hline LVEF, \% & $53.5( \pm 9.3)$ \\
\hline LVEDD, cm & $4.87( \pm 0.56)$ \\
\hline $\mathrm{LA}, \mathrm{cm}$ & $3.9( \pm 0.6)$ \\
\hline Ascending aorta, $\mathrm{cm}$ & $3.60( \pm 0.49)$ \\
\hline IVSD, cm & $1.1( \pm 0.2)$ \\
\hline
\end{tabular}

the artery diameter percentage change that is showed as endothelial functions in FMD test $(r=+0.379, p=0.04)$. The relationship between HDL/LDL ratios and FMD percentage change is shown in Figure 2.

\section{Discussion}

Atherosclerosis is a multifactorial disease caused by inflammatory, immunological and genetic events ${ }^{(6)}$. Endothelial dysfunction is one of the main mechanisms in atherosclerotic process. Endothelial dysfunction not

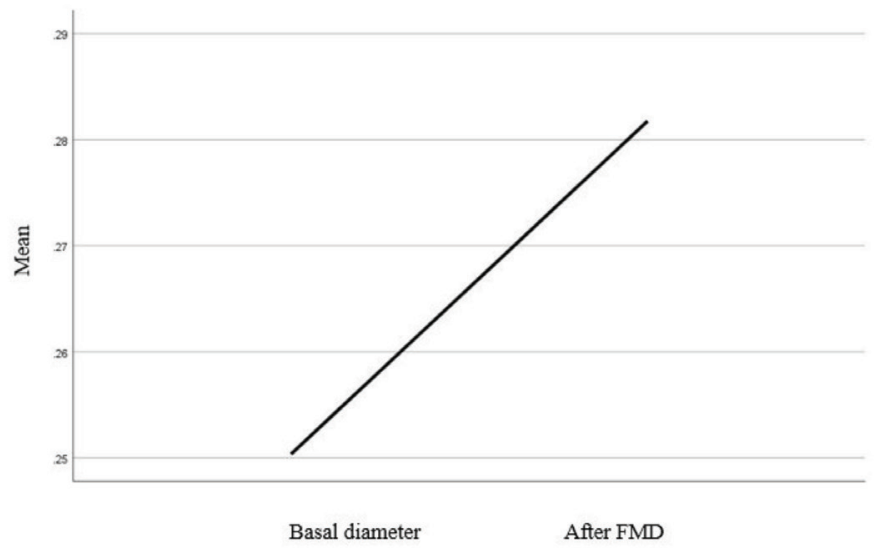

Figure 1. Radial artery diameter change graph in flow mediated vasodilation test

FMD: Flow mediated vasodilation

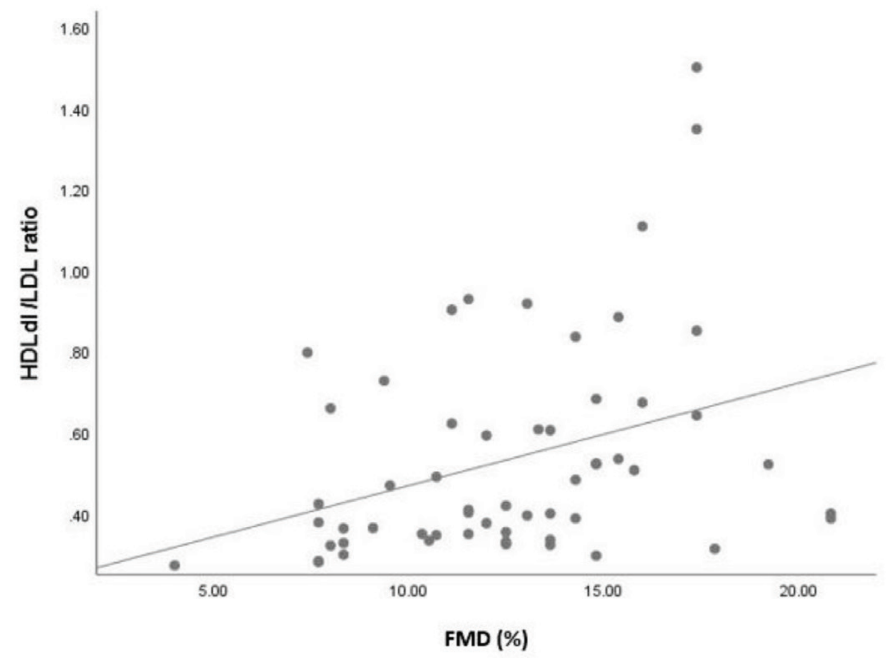

Figure 2. Relationship between HDL/LDL ratios and FMD percentage diameter change

HDL: High density lipoprotein, LDL: Low density lipoprotein, FMD: Flow mediated vasodilation 
Table 4. Arterial diameter and percentage change in flow mediated vasodilation test

\begin{tabular}{|l|l|l|l|}
\hline FMD test & Basal diameter & Diameter after FMD & $\begin{array}{l}\text { Percentage diameter change } \\
\text { after FMD }\end{array}$ \\
\hline Mean $( \pm$ standard deviation), cm & $0.25( \pm 0.029)$ & $0.28( \pm 0.033)$ & $12.61( \pm 3.62)$
\end{tabular}

only plays a role in the first step of the atherosclerotic process that causes plaque formation, but also causes plaque to grow, cracking the plaque and trigger thrombogenic events ${ }^{(12)}$. The endothelium produces NO, which inhibits the cellular pathways of inflammation, proliferation, and thrombosis ${ }^{(13,14)}$. In normal endothelium, acetylcholine causes vasodilation and increases blood flow by stimulating NO release, while in the presence of endothelial dysfunction, it directly stimulates vascular smooth muscle cells and leads to vasoconstriction ${ }^{(1,13,14)}$.

Vascular endothelial cell is the main target of pathological or mechanical injury caused by some risk factors such as smoking, increased systolic blood pressure, high total cholesterol, and low HDL cholesterol level ${ }^{(15)}$. It has been observed that normal HDL taken from healthy subjects exhibits direct anti-atherogenic effects by modulating vascular endothelial functions ${ }^{(16-18)}$. HDL stimulates endothelial NO production by activating endothelial NO synthase (eNOS), and also has antioxidant, anti-inflammatory and antithrombotic effects ${ }^{(19-22)}$. We planned our study to evaluate the effect of HDL/LDL ratios on endothelial functions in patients with CAD under the same antithrombotic and anticoagulant treatment regimen.

Epidemiological studies have shown that HDL cholesterol has a protective effect against atherosclerosis, but the mechanism is not known exactly ${ }^{(23,24)}$. Experimental animal studies have shown that HDL infusion acutely improves endothelial function ${ }^{(25,26)}$. In vitro, HDL has been shown to protect endothelial cells against the damaging effects of LDL and to prevent oxidative modification of LDL particles ${ }^{(27)}$.

The effects of HDL/LDL concentration ratios on vascular endothelial function in healthy individuals were evaluated on the basis of flow-mediated vasodilation response, which is a marker of endothelial function, and in our study, we found a weak positive correlation between HDL/LDL ratios and endothelial function.

In a study involving 26 patients who underwent routine diagnostic cardiac catheterization, it was found that high HDL levels improved intimal vasoconstriction in coronary arteries regardless of atherosclerotic wall thickness ${ }^{(28)}$. Plasma HDL cholesterol concentration is a strong independent predictor of NO-induced peripheral vasodilation in patients with hyperlipidemia, diabetes mellitus, and $\mathrm{CAD}^{(29-31)}$. As in animals, in individuals with hypercholesterolemia or low HDL, intravenous infusion of soluble HDL has been shown to improve the endothelium-dependent peripheral vasodilation by increasing NO bioavailability ${ }^{(32,33)}$. Oxidized LDLs are a potent inducer of endothelial dysfunction. The protective effects of HDL on endothelial function are very important due to its capacity to resist the destructive effects of oxidized LDL ${ }^{(17,34)}$. Low plasma HDL concentration is an independent predictor of endothelial dysfunction in healthy individuals and atherosclerotic patients ${ }^{(10)}$. Our study confirms this information, and our study demonstrated that as HDL/ LDL ratio increased, flow-mediated dilatation which evaluates endothelial function non-invasively, also increased.

\section{Study Limitations}

The single-center nature of our study is one of the limitations. The low number of patients may have reduced the power of the study. We believe that the strength of the weak correlation between HDL/LDL ratio and endothelial functions would increase if there were a higher number of patients. Another limitation of our study may be that 
endothelial functions were not evaluated by nitroglycerine mediated vasodilation test. The high ratio of male gender in the study may prevent the generalization of the study results over the population.

\section{Conclusion}

$\mathrm{HDL} / \mathrm{LDL}$ ratio is related to endothelial functions in patients with CAD. As the HDL/LDL ratio increases, flow-mediated dilatation increases. We think that this study will be a pioneer to randomized studies that will be conducted on parameters affecting endothelial functions in patients with $\mathrm{CAD}$.

\section{Ethics}

Ethics Committee Approval: Ethics committee approval of our study was obtained from EGE University Faculty of Medicine Clinical Research Ethics Committee on 26.12.2017 with the decision number 17-12.1/22.

Informed Consent: A signed informed consent form was obtained from the patients included in this study.

Peer-review: Externally peer-reviewed.

\section{Authorship Contributions}

Surgical and Medical Practices: M.K., M.A., Concept: E.S., M.A., Design: M.K., E.S., Data Collection or Processing: M.K., Analysis or Interpretation: M.K., E.S., Literature Search: M.K., M.A., Writing: M.K., E.S.

Conflict of Interest: The authors declared that there was no conflict of interest related to this article.

Financial Disclosure: The authors declared that this study received no financial support.

\section{References}

1. Celermajer DS. Endothelial dysfunction: Does it matter? Is it reversible? J Am Coll Cardiol 1997;30:325.

2. Baumgartner-Parzer SM, Waldhäusl WK. The endothelium as a metabolic and endocrine organ: its relation with insulin resistance. Exp Clin Endocrinol Diabetes 2001;109(Suppl 2):S166-79.

3. Rajendran P, Rengarajan T, Thangavel J, et al. The vascular endothelium and human diseases. Int J Biol Sci. 2013;9:1057-69.

4. Godo S, Shimokawa H. Endothelial Functions. Arterioscler Thromb Vasc Biol 2017;37:e108-14.
5. Cohn JN. Arterial compliance to stratify cardiovascular risk: more precision in therapeutic decision making. Am J Hypertens 2001;14:258-63.

6. Esper RJ, Nordoby RA, Vilarino JO, Paragano A, Cacharron JL, Macharado RA. Endothelial dysfunction: a comprehensive appraisal. Cardiovasc Diabetol 2006;5:4.

7. Cannon $\mathrm{CP}$, Braunwald $\mathrm{E}, \mathrm{McCabe} \mathrm{CH}$, et al. Intensive versus moderate lipid lowering with statins after acute coronary syndromes. N Engl J Med 2004;350:1495-504

8. Akçakoyun M. Koroner arter hastalı̆̆ $\breve{g}_{1}$ olgularında koroner risk faktörleri ile endotel fonksiyonları arasındaki ilişki (uzmanlık tezi). İstanbul: Koşuyolu Kalp Eğitim ve Araştırma Hastanesi; 2004.

9. Calabresi L, Gomaraschi M, Franceschini G. Endothelial protection by high-density lipoproteins: from bench to bedside. Arterioscler Thromb Vasc Biol 2003;23:1724-31.

10. Gomaraschi M, Baldassarre D, Amato M, et al. Normal vascular function despite low levels of high-density lipoprotein cholesterol in carriers of the apolipoprotein A-I(Milano) mutant. Circulation 2007;116:2165-72.

11. Mineo C, Shaul PW. Novel biological functions of high-density lipoprotein cholesterol. Circ Res 2012;111:1079-90.

12. Dursunoğlu N, Dursunoğlu D. Obstrüktif uyku apnesi sendromu, endote disfonksiyonu. Tüberküloz Toraks Derg 2005;53:299-306.

13. Mart'inez-Gonzalez J, Badimon L. Mechanisms underly- 'ing the cardiovascular effects of COX-inhibition: benefits andrisks, Curr Pharm Des 2007;13:2215-27.

14. Julve J, Llaverias G, Blanco-Vaca F, Escola-Gil JC. Seeking novel targets for improving in vivo macrophage-specificreverse cholesterol transport: translating basic science into new therapies for the prevention and treatment of atherosclerosis. Curr Vasc Pharmacol 9:220-37.

15. Eren E, Yilmaz N, Aydin O. High density lipoprotein and it's dysfunction. Open Biochem J 2012;6:78-93.

16. de Goma EM, de Goma RL, Rader DJ. Beyond high-density lipoprotein cholesterol levels evaluating high-density lipoprotein function as influenced by novel therapeutic approaches. J. Am Coll Cardiol 2008;51:2199-211.

17. Movva R, Rader DJ. Laboratory Assessment of HDL Heterogeneity and Function. Clin Chem 2008;54:788-800.

18. Mineo C, Shaul PW. PON-dering differences in HDL function in coronary artery disease. J Clin Invest 2011;121:2545-8

19. Yuhanna IS, Zhu Y, Cox BE, et al. High-density lipoprotein binding to scavenger receptor-BI activates endothelial nitric oxide synthase. Nat Med 2001;7:853-7.

20. Navab M, Hama SY, Cooke CJ, et al. Normal high density lipoprotein inhibits three steps in the formation of mildly oxidized low density lipoprotein: step 1. J Lipid Res 2000;41:1481-94.

21. Campbell S, Genest J. HDL: clinical equipoise and vascular endothelial function. Exp Rev Cardiovasc Ther 2013;11:343-53.

22. Assmann G, Gotto Jr AM. HDL cholesterol and protective factors in atherosclerosis. Circulation 2004;109(Suppl 1):III8-14.

23. Gordon T, Castelli WP, Hjortland MC, Kannel WB, Dawber TR. High density lipoprotein as a protective factor against coronary heart disease: the Framingham study. Am J Med 1977;62:707. 
24. Barter PJ, Rye KA. High density lipoproteins and coronary heart disease. Atherosclerosis 1996;121:1-12.

25. Matsuda Y, Hirata K, Inoue N, et al. High density lipoprotein reverses inhibitory effect of oxidized low density lipoprotein on endotheliumdependent arterial relaxation. Circ Res 1993;72:1103.

26. Galle J, Ochslen M, Schollmeyer P, Wanner C. Oxidized lipoproteins inhibit endothelium-dependent vasodilation: effects of pressure and highdensity lipoprotein. Hypertension 1994;23:556.

27. Parthasarathy S, Barnett J, Fong LG. High density lipoprotein inhibits the oxidative modification of low-density lipoprotein. Biochim Biophys Acta 1990;1044:275

28. Zeiher AM, Scha"chinger V, Hohnloser SH, Saurbier B, Just H. Coronary atherosclerotic wall thickening and vascular reactivity in humans: elevated high-density lipoprotein levels ameliorate abnormal vasoconstriction in early atherosclerosis. Circulation 1994;89:2525.

29. Kuvin JT, Patel AR, Sidhu M, et al. Relation between high-density lipoprotein cholesterol and peripheral vasomotor function. Am J Cardiol 2003;92:275-9.
30. Lupattelli G, Marchesi S, Roscini AR, et al. Direct association between highdensity lipoprotein cholesterol and endothelial function in hyperlipemia. Am J Cardiol 2002;90:648-50.

31. Zhang X, Zhao SP, Li XP, Gao M, Zhou QC. Endothelium-dependent and -independent functions are impaired in patients with coronary heart disease. Atherosclerosis 2000;149:19-24.

32. Spieker LE, Sudano I, Hurlimann D, et al. High-density lipoprotein restores endothelial function in hypercholesterolemic men. Circulation 2002;105:1399-402.

33. Bisoendial RJ, Hovingh GK, Levels JH, et al. Restoration of endothelial function by increasing high-density lipoprotein in subjects with isolated low high-density lipoprotein. Circulation 2003;107:2944-8.

34. Mineo C, Deguchi H, Griffin JH, Shaul PW. Endothelial and antithrombotic actions of HDL. Circ Res 2006;98:1352-64. 